\title{
A PESCA NO RESERVATÓRIO DA HIDRELÉTRICA DE BALBINA (AMAZONAS, BRASIL)
}

\author{
Geraldo Mendes dos SANTOS ${ }^{1}$ Arnaldo Braga de OLIVEIRA $\mathrm{Jr}^{2}$
}

\begin{abstract}
RESUMO - A hidrelétrica de Balbina localiza-se no rio Uatumã, a $170 \mathrm{~km}$ de Manaus, pela $\mathrm{BR} / 174$. O enchimento do reservatório iniciou-se em outubro/87 e a usina começou a funcionar em fevereiro de 1989, com apenas uma das suas cinco turbinas. Apesar da redução da diversidade da ictiofauna e dos danos ambientais e sociais decorrentes do represamento, algumas espécies de peixes proliferaram no reservatório, resultando no incremento da atividade pesqueira, praticada basicamente sobre os estoques de tucunaré (Cichla spp). A explotação desta espécie, iniciada logo após a formação do reservatório, vem sendo feita até os dias atuais, com uma produção média em torno de 500 toneladas/ano e da qual participam 100 a 160 pescadores profissionais, além de dezenas de amadores, Os barcos de pesca tem baixa capacidade, entre 800 e $5.000 \mathrm{~kg}$ e o pescado é mantido e transportado em gelo adquirido em Manaus. Devido sobretudo às grandes dimensões do reservatório, cerca de $2360 \mathrm{~km}^{2}$, a densidade de pescadores é muito baixa, em torno de 0,04 a $0,07 / \mathrm{km}^{2}$. O presente trabalho descreve a atividade pesqueira praticada, analisa os níveis de produção e discute critérios que deveriam ser empregados com vistas ao aperfeiçoamento do manejo deste importante recurso natural.
\end{abstract}

Palavras-chave: Pesca, Recursos pesqueiros, Hidrelétrica, Balbina,Amazônia

\section{The Fishery in the Balbina Reservoir (Amazonas State, Brazil)}

SUMMARY - The Balbina hydroelectric power plant is located on the Uatumã River, $170 \mathrm{~km}$ from Manaus. The reservoir started to fill in 1987 and operations began in 1989, with one of the five planned turbines. Despite the reduction in fish diversity and other environmental and social damages that resulted from its installation, some species of fish proliferated in the reservoir, notably the tucunare (Cichla $\mathrm{sp}$ ), which is the target for intensive fishing. The exploitation of this species began as soon as the reservoir was filled, and has been maintained since, with a median production of 500 ton/yr, involving 100 to 160 professional fisherman as well as many amateur fishermen. The boats used have low capacity, between 800 and $5,000 \mathrm{~kg}$. The fishes are maintained and transported in ice arising from Manaus. Due to the great dimensions of the reservoir, around $2360 \mathrm{~km}^{2}$, the density of fishermen is very low, about 0.04 and $0.07 / \mathrm{km}^{2}$. This study describes the fishery activities, analyses the levels of production and discusses criteria that should be adopted in order to achieve an appropriate management of this important natural resource.

Key-words: Fisheries, Fish resources, Ichthyofauna, Hydroelectric dam, Amazon

\section{INTRODUÇÃO}

Ao longo de toda a história da Amazônia, incluindo o período anterior ao seu descobrimento pelos europeus, a pesca de água doce tem sido uma das mais importantes atividades humanas (Furtado, 1981). Mesmo na atualidade, frente ao intenso desenvolvimento do setor industrial e a constante degradação do meio ambiente, a pesca continua sendo o sustentáculo da economia regional e a fonte básica da alimentação das populações locais.

A média do consumo anual de pescado na Amazônia é estimada em cerca de 270.000 toneladas (Merona,

1 Instituto Nacional de Pesquisas da Amazônia - CPBA, Cx. P. 478 Cep. 69.083-000 Manaus - AM. e-mail: gsantos@inpa.gov.br

2 Instituto do Meio Ambiênte do Acre - Rio Branco, AC - e-mail: cichla@hotmail.com 
1993), mas o seu potencial é bem maior, em torno de 902.000t/ano (Bayley \& Petrere Jr, 1989), o que corresponde aproximadamente à produção total de pescado de água doce explotado em águas brasileiras (Okada et al., 1996).

Tomando-se a comercialização de pescado a um preço em torno de um real por quilo, no início da cadeia de comercialização, deduz-se que a pesca movimenta cerca de 270 milhões por ano, sendo que a esse valor devem ser agregado ainda cerca de 1,2 milhões, oriundos do comércio de aproximadamente 15 milhões de peixes ornamentais (Leite \& Zuanon, 1991).

A produção de pescado na Amazônia é decorrente de duas modalidades básicas de pesca: uma de subsistência e outra comercial (Bayley \& Petrere Jr., 1989), tendo a primeira um carater difuso, pois não está centrada em nenhuma área ou estoque específico, ao passo que a segunda explota poucas espécies e é voltada para a comercialização nos grandes centros consumidores da região e parte para exportação.

Além destas duas modalidades tradicionais, as quais são realizadas em ambientes naturais como lagos e rios, existe uma outra, mais recente, praticada em reservatórios de hidrelétricas e que produz uma quantidade apreciável de pescado (Petrere Jr.,1992).

Existem atualmente cinco grandes reservatórios de hidrelétricas na Amazônia brasileira, sendo que dois deles (Tucuruí, no rio Tocantins-PA e Samuel, no Jamari-RO) já se constituem em grandes centros produtores de pescado, em escala comercial.
Segundo Petrere Jr. (1996), entre outubro de 1987 e setembro de 1988 foram capturados 1.424 toneladas de pescado em Tucuruí, sendo que a maior parte da producão é de tucunaré $(57 \%)$ e pescada (21\%). De acordo com Santos (1996), no reservatório de Samuel a pesca está centrada sobre os estoques de tucunaré (Cichla sp); aracu (Schizodon fasciatus) e, em menor escala, mapará (Hypophthalmus sp); entretanto inexistem coletas sistematizadas de dados de desembarque pesqueiro neste local.

Nos reservatórios de Paredão, em Roraima e Curuá-Una, no Pará, não existem dados de desembarque pesqueiro, mas a proliferação de tucunarés e outras espécies de valor comercial alí verificada (Holanda, 1982; Vieira, 1982; Ferreira, 1984), certamente tem favorecido a pesca de subsistência ou mesmo a comercial, em pequena escala.

No reservatório de Balbina vem sendo realizada uma intensa atividade pesqueira, centrada sobre os estoques de tucunarés e da qual participam cerca de 100 a 160 pescadores, responsáveis por uma produção de até 706 toneladas/ano.

Apesar da pesca comercial em Balbina ter-se iniciado em 1988, cerca de um ano após o barramento do rio Uatumã, as coletas de dados de desembarque pesqueiro só foram iniciadas em 1991. A partir de 1996, com a pavimentação do trecho da BR 174 que liga Manaus a Balbina, tanto a pesca comercial como a amadora, de caráter esportivo, vêm sendo bastante incrementadas.

Estes fatos indicam que os peixes existentes no reservatório representam 
um recurso sumamente importante, não somente para a pesca, mas também para o setor turístico que vem crescendo paulatinamente. Por essa razão, é óbvio que informações técnicas e cientificas sobre a ictiofauna e o pescado são de fundamental importância para uma melhor compreensão e gerenciamento dos recursos naturais disponíveis em Balbina. O presente trabalho se insere neste contexto, e visa descrever a atividade pesqueira, analisar os dados de produção e apontar algumas alternativas para o manejo dos recursos pesqueiros ali existentes.

\section{CARACTERIZAÇÃO DO AMBIENTE}

A bacia hidrográfica do rio Uatumã (Fig.1) localiza-se entre os paralelos $0^{\circ} \mathrm{e} 3^{\circ} \mathrm{S}$ e os meridianos $58^{\circ} \mathrm{e}$ $61^{\circ} \mathrm{O}$, inteiramente no estado do Amazonas, perfazendo uma área de drenagem de $70.600 \mathrm{~km}^{2}$. Ela se situa em área de floresta tropical, com diversas composições florísticas, destacando-se a mata de terra firme, sobre solo argiloso e a campinarana, sobre solo arenoso, as quais correspondem a cerca de $70 \%$ e $15 \%$, respectivamente, da área que foi ocupada pelo reservatório da hidrelétrica de

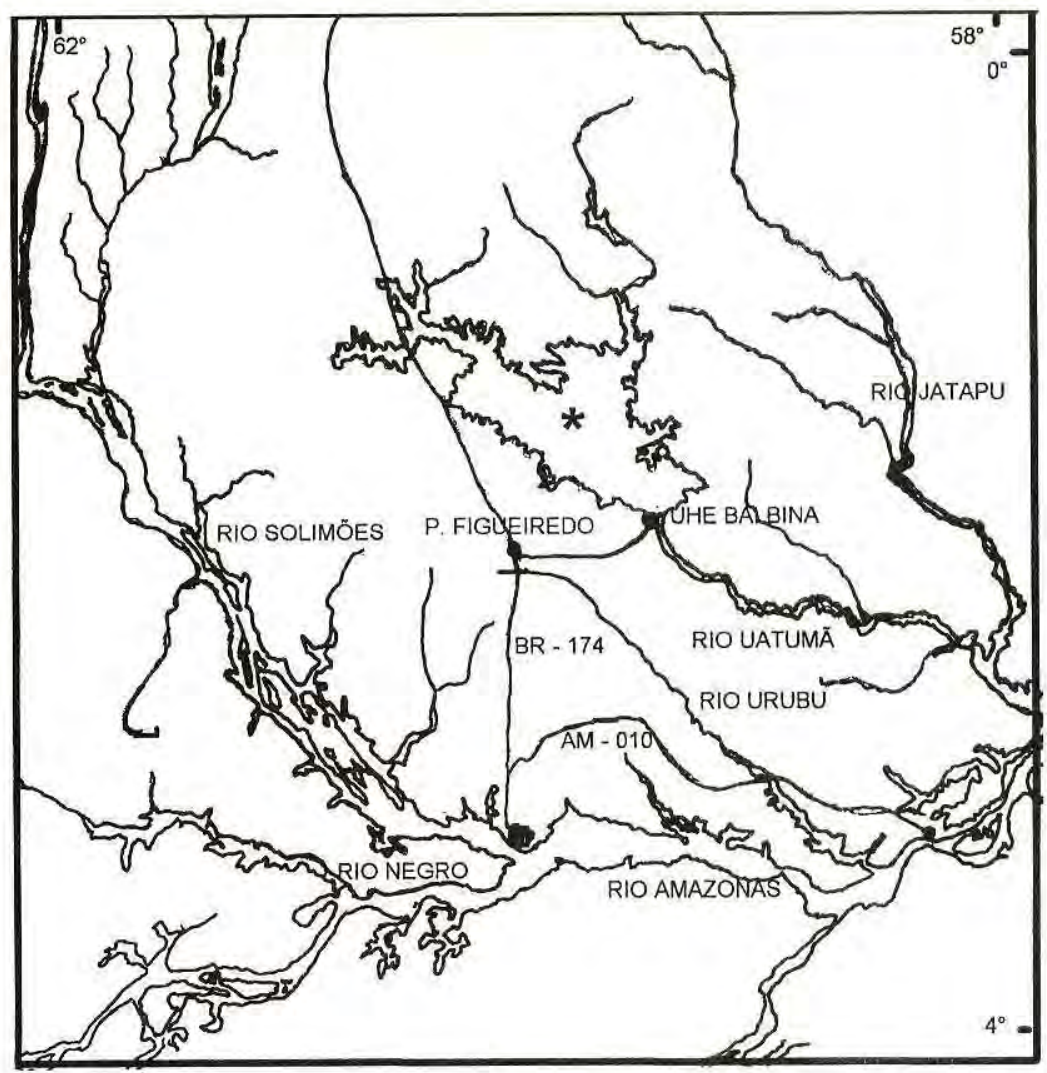

Figura 1. Mapa da região, com indicação do Reservatório da UHE Balbina (*) 
Balbina (Eletronorte, s.d).

$\mathrm{O}$ rio Uatumã tem águas cinzaescuras, com características mais semelhantes às águas pretas, de acordo com a tradicional classificação dos rios amazônicos (Sioli, 1967). A hidrelétrica de Balbina está situada no município de Presidente Figueiredo, estado do Amazonas. Ela tem uma capacidade nominal de $250 \mathrm{MW}$, dispondo de quatro vertedouros e cinco turbinas. A cota normal do reservatório está em torno de $50 \mathrm{~m}$, sendo 51,2 na máxima e $48 \mathrm{~m}$ na mínima. A baixa declividade do terreno resultou numa enorme área de inundação, com 2.360 $\mathrm{km}^{2}$, profundidade média de $7,5 \mathrm{~m}$, comprimento de $210 \mathrm{~km}$ e larguras média e máxima de 11 e $75 \mathrm{~km}$, respectivamente (Eletronorte, s.d.).

Toda a água acumulada no reservatório é destinada à operação das turbinas; assim sendo, os vertedouros estão quase sempre fechados, mesmo durante $o$ período de cheia normal. Segundo informações obtidas junto ao setor operacional da Eletronorte, em toda sua existência, apenas em duas ocasiões eles entraram em funcionamento: uma logo após a construção da hidrelétrica, quando apenas uma turbina estava operando e a outra, entre maio e junho/96, quando ocorreram fortes chuvas na área e o reservatório se encontrava com um volume dágua acima de sua cota normal.

A hidrelétrica de Balbina tem sua história marcada por grande celeuma, principalmente por causa das dimensões exageradas de seu reservatório e baixa capacidade de produção de energia, de apenas $1 \mathrm{~kW} / \mathrm{ha}$ (Goodland et al., 1993). Para se ter uma idéia mais clara desta cifra, basta citar a UHE Tucurui, que tem um reservatório aproximadmente do mesmo tamanho e apresenta uma capacidade 15 vezes maior. Hidrelétricas bastante eficientes como Paulo Afonso chegam a produzir cerca de $2500 \mathrm{~kW} / \mathrm{ha}$.

Durante o desenvolvimento deste estudo, realizado dez anos após a instalação da hidrelétrica de Balbina, não foi detectada a presença de plantas aquáticas no reservatório, exceto ocorrências esporádicas de gramíneas (Cyperaceae) que crescem sobre troncos podres flutuantes e de aglomerados de algas filamentosas que ficam aderidas aos troncos e galhos.

Exceto o canal principal do rio, que continua livre, praticamente todo o restante da área do reservatório é formado por "paliteiro", que são árvores mortas pelo represamento. Nos terrenos mais elevados restaram centenas de ilhas espalhadas pelo interior do reservatório, sendo que em suas margens ocorre grande quantidade de troncos e galhos que ficam totalmente expostos quando o nivel do reservatório baixa (Fig. 2). No rigoroso verão de 1997, foram observados numerosos focos de queimadas ao redor e no interior das ilhas, com formação de intensas nuvens de fumaça que se propagavam por toda a área, chegando a prejudicar a navegação fluvial.

A maioria das queimadas é provocada sem nenhum objetivo, e geralmente é decorrente da propagação de fogo deixado no local pelos pescadores, quando da preparação de comida. Em outros casos, ela é proposital, com a finalidade de limpeza do terreno para plantio de fruteiras, como 


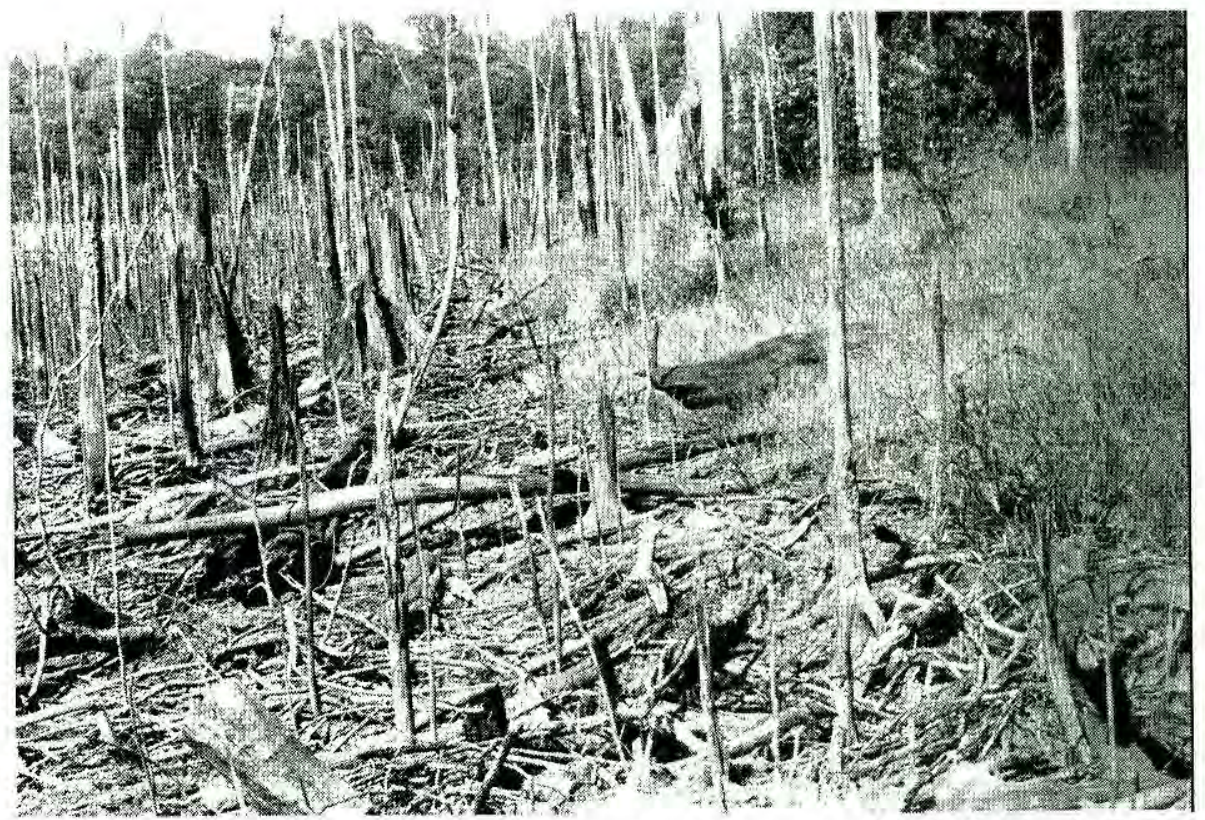

Figura 2. Amontoado de troncos e galhos de árvores mortas no reservatório de Balbina (paliteiros), em agosto de 1997.

melancia e banana ou simplesmente para facilitar o atracamento das embarcações.

Vários estudos sobre a qualidade da água foram desenvolvidos na fase anterior à implantação do reservatório, através do programa de avaliação de impactos ambientais da UHE Balbina (Camargo \& Miyai, 1983; Ribeiro, 1984). Alguns dos parâmetros físicoquímicos estudados encontram-se sumarizados na Tabela 1. Após a instalação da hidrelétrica, o laboratório de Limnologia da Eletronorte, instalado no local, vem fazendo rotineiramente o monitoramento da qualidade da água, sendo os dados apresentados em relatórios técnicos desta empresa.

A confrontacão de alguns dados limnológicos do Uatumã obtidos antes e após a instalação da hidrelétrica permite concluir que as principais modificações ocorridas na área do reservatório referem-se à transparência da água, que variava de 0,8 a $1,8 \mathrm{~m}$ e passou para 1,9 a $3,0 \mathrm{~m}$, bem como à profundidade, cuja máxima era cerca de $6 \mathrm{~m}$ e passou para aproximadamente $35 \mathrm{~m}$.

\section{MATERIAL E MÉTODOS}

Os dados sobre a pesca em Balbina foram obtidos durante as excursões feitas pelos autores, entre 1995 e 1997, para a realização de estudos ictiofaunísticos no âmbito de um projeto institucional do INPA em cooperação com a Eletronorte (PPI 3280 - Energia e Meio Ambiente).

Para o estudo da ictiofauna foram realizadas coletas trimestrais, utilizandose uma bateria de malhadeiras com diversos tamanhos de malhas, bem como anzóis e currico. Os dados de produção pesqueira foram obtidos junto à Associação dos Pescadores de Balbina, 
Tabela 1. Amplitude de variação de parâmetros limnológicos no curso principal do rio Uatumã, antes e depois da instalação da hidrelétrica de Balbina. Medidas tomadas na superfície ou em profundidades abaixo de $4 \mathrm{~m}$, na área do reservatório. Fonte: Camargo,A.F.M. \& Miyai,R.K.,1983; Eletronorte, 1997.

\begin{tabular}{lcc|c}
\hline & Fev-Mar/83 & Mai -Jun/83 & Jan - Dez/96 \\
\hline Condutividade ( S/cm) & $14,0-30,0$ & $10,9-14,2$ & $8,8-16,2$ \\
Temperatura & $32,0-34,0$ & $28,0-29,0$ & $29,0-32,0$ \\
$\mathrm{pH}$ & $4,2-5,9$ & $4,1-5,9$ & $5,8-7,0$ \\
Transparência (m) & $1,2-1,8$ & $0,8-1,2$ & $1,9-3,0$ \\
Concentração de oxigênio (mg/l) & $5,5-7,0$ & $4,3-5,0$ & $1,1-8,1$ \\
Material suspensão (mg/l) & $1,4-6,4$ & $2,9-14,3$ & \\
Dureza (odH) & $0,1-0,3$ & $0,1-0,2$ & \\
$\mathrm{Ca}$ (mg/l) & $0,2-1,1$ & $0,0-0,8$ & \\
$\mathrm{Mg}_{\text {(mg/l) }}$ & $0,3-1,3$ & $0,2-0,8$ & \\
$\mathrm{SiO}_{3}(\mathrm{mg} / \mathrm{l})$ & $1,0-3,2$ & & \\
$\mathrm{PO}_{4}(\mathrm{~g} / \mathrm{l})$ & $2,5-21,0$ & & \\
$\mathrm{NH}_{4}(\mathrm{~g} / \mathrm{l})$ & $12,0-58,0$ & & \\
$\mathrm{Pigmento} \mathrm{total}$ & $1,6-12,0$ & & \\
\hline
\end{tabular}

bem como em visitas ao porto de desembarque, situado na margem direita do reservatório, próximo à barragem e também de entrevistas com pescadores e comerciantes de pescado. Os dados referentes à parâmetros físico-quimicos foram obtidos junto ao laboratório de Limnologia da Eletronorte, situado em Balbina.

\section{RESULTADOS}

\section{Locais e apetrechos da pesca}

A pesca em Balbina é efetuada apenas no reservatório e está voltada quase que exclusivamente para a explotação do estoque de tucunarés. As principais áreas de pesca situam-se normalmente entre 30 e $100 \mathrm{~km}$ acima da barragem e correspondem aos trechos inferiores dos afluentes que existiam na área e que foram inundados pelo represamento. Os locais, no entanto, não são fixos, podendo variar a cada viagem, dependendo da detecção de cardumes.

O único aparelho permitido para a pesca no reservatório é o anzol, o qual é empregado tanto na forma de currico como linhada-de-mão e de vara. No caso de linhadas, são empregadas iscas de peixe inteiro ou em pedaços.

Os peixes comumente utilizados inteiros são a oraninha (Hemiodus goeldii) e a piaba (Hemmigramus levis), ambos de pequeno porte, com comprimento máximo de 4 e $7 \mathrm{~cm}$, respectivamente e muito frequentes no reservatório. Pedaços de peixes para isca são retirados dos primeiros peixes capturados ou, preferencialmente, do ventre ou do pedúnculo do próprio tucunaré.

$\mathrm{O}$ estudo realizado sobre as táticas alimentares do tucunaré no reservatório de Balbina (Oliveira Jr, 1998), mostra que esta espécie é exclusivamente piscivora e que os peixes utilizados como isca, acima referidos, constituem-se, exatamente, na sua principal fonte alimentar. 
O currico é formado por um ou mais anzois, engastados num suporte metálico ou plástico. Sua utilização é feita da seguinte maneira: o aparelho, preso na extremidade de um longo fio de nailon, é lançado na água; imediatamente após o lançamento, é puxado aos poucos, ocasião em que o tucunare investe sobre ele, na tentativa de agarrá-1o. Quando isso ocorre, é puxado bruscamente, com o objetivo de fisgar o peixe. Em muitos casos, o tucunaré nem chega a abocanhar o anzol, podendo ser fisgado pela superfície do corpo ou mesmo apenas arrastado para a canoa.

Nos primeiros anos do reservatório, era empregado apenas o currico industrializado, em forma de isca artificial, mas este acabou sendo substituído por um currico artesanal feito pelos próprios pescadores a partir de colher de alumínio cortada em pedaços (Fig. 3.). Embora afirmem que o tucunarè tenha aprendido a reconhecer e evitar o currico industrializado, é provável que as principais razões para que isso ocorresse tenham sido o seu custo elevado e suas sucessivas perdas, provocadas pela mordida da piranha.

De acordo com nossas observações, o anzol é mais utilizado quando os cardumes se encontram parados, geralmente nas partes mais profundas do reservatório, ao passo que o currico funciona melhor quando os cardumes se encontram mais próximos à superfície e estão em plena atividade, geralmente perseguindo suas presas. $\mathrm{O}$ currico tem a vantagem de ser mais seletivo para a pesca do tucunaré, pois evita a captura de outros peixes carnívoros e indesejáveis, como a piranha e o peixe-cachorro.

O barco de pesca é uma canoa de madeira, no meio da qual é instalada uma caixa revestida de alumínio, onde

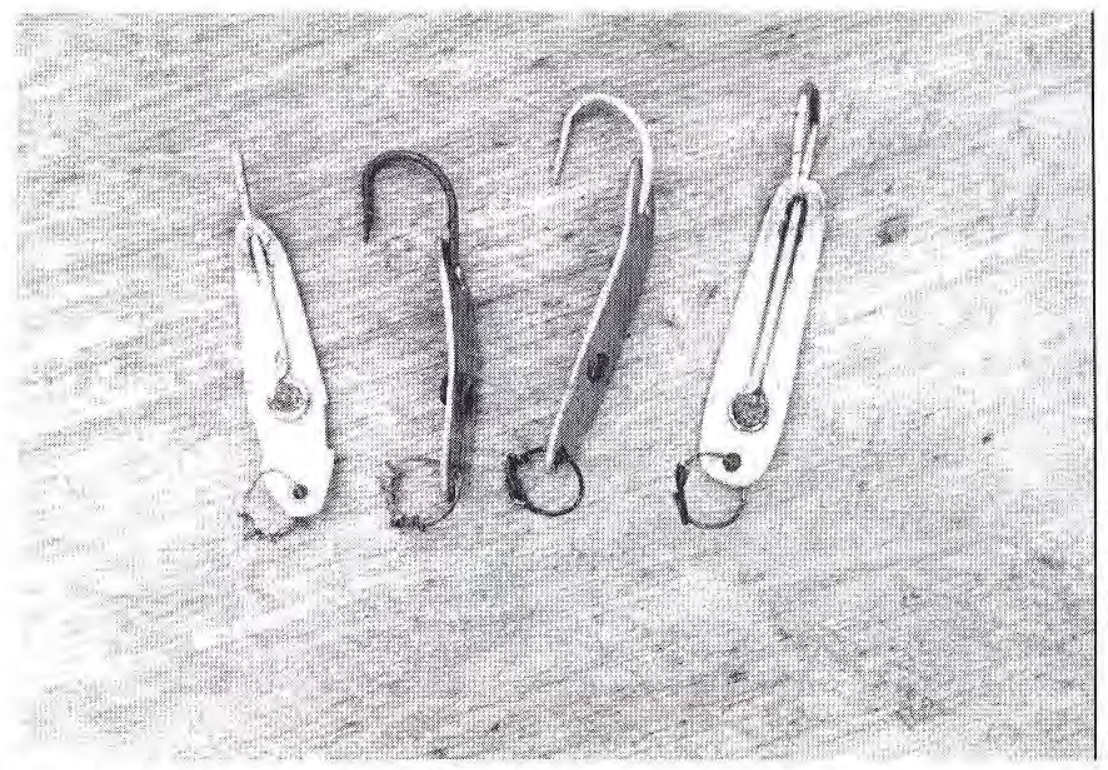

Figura 3. Currico artesanal - principal aparelho de pesca do tucunaré em Balbina. 
é acondicionado gelo. O maior barco em operação tem capacidade de 5.000 $\mathrm{kg}$ e o segundo de $2.000 \mathrm{~kg}$, sendo os demais bem menores, comportando entre 800 e $1.000 \mathrm{~kg}$.

Uma vez na área de pesca, o barco é ancorado nas margens das ilhas, geralmente onde já existe local preparado para acampamento e daí os pescadores saem para pescar nos arredores com suas pequenas canoas de madeira, chamadas montaria.

A pesca de tucunare é feita somente durante o dia, pois esse é período em que este peixe está em atividade. À noite, com facho de luz, podem ser vistos indivíduos parados, próximos às margens, entretanto os pescadores não utilizam zagaia ou outros aparelhos perfurantes, próprios para a pesca noturna, provavelmente para se evitar a mutilação do pescado e o consequente prejuízo de sua qualidade para o mercado.

Enquanto estão em operação, os pescadores mantém o pescado com gelo em pequenas caixas de isopor; ao retornarem ao acampamento, o pescado é pesado e transferido para a caixa do barco, onde é misturado ao gelo, na proporção aproximada de 1,5:1. Quando a carga do barco está completa a tripulação retorna ao porto de desembarque para fazer a entrega ao comprador.

$\mathrm{O}$ descarregamento no porto pode ser imediato, como também demorar um ou mais dias, já que o pescado só é transferido para o caminhão quando existe quantidade suficiente para completar sua carga. Uma vez que isso ocorre, o pescado é colocado em carroceria de caminhão, misturado com gelo, e protegido por folhas de papelão e lona e em seguida despachado para a venda em Manaus.

\section{Composição do Pescado e Estatística Pesqueira}

A pesca comercial no reservatório de Balbina visa praticamente apenas o tucunaré. Ocasionalmente outros peixes de grande porte, como a piranha preta (Serrasalmus rhombeus), aruanã (Osteoglosssum bicirrhosum) e traira (Hoplias malabaricus), são também aproveitados, servindo normalmente para alimentação dos pescadores e seus familiares.

Foram encontradas três espécies de tucunarés no reservatório de Balbina: Cichla monoculus (comum); Cichla temensis (paca ou pinima) e Cichla sp. (açu). Apesar de alcançar menor tamanho, em torno de $30 \mathrm{~cm}$ de comprimento padrão, o tucunarécomum é o mais abundante, chegando a aproximadamente $90 \%$ da produção total. As outras duas espécies alcançam cerca de $75 \mathrm{~cm}$ de comprimento e são menos abundantes, com frequências aproximadamente iguais entre si.

Tem-se verificado no reservatório de Balbina, um número bastante elevado de tucunarés acometidos de uma magreza extremamente acentuada, sendo denominados de "afó" e "mukao". Quando isso ocorre, o peixe fica bastante afilado e disforme, com a cabeça desproporcionalmente grande em relação ao restante do corpo. Tem-se observado que os peixes neste estado tem a capacidade natatória bastante prejudicada, ficando imobilizados ou escondidos junto a troncos ou próximo às margens. 
Os peixes imprestáveis para a alimentação humana, como os tucunarés enfermos e jovens, com tamanho abaixo de $15 \mathrm{~cm}$, bem como as demais espécies indesejáveis, são normalmente lançadas ao rio ou então utilizadas como isca. Dos grandes exemplares da piranha preta normalmente se retira o filé, que tem boa aceitação comercial.

A produção pesqueira média, verificada em Balbina desde 1991 é de aproximadamente 500 toneladas/ano, havendo um pico máximo, de $706 \mathrm{t}$, em 1993 e uma tendência de declínio a partir deste ano, chegando ao mínimo de $287 \mathrm{t}$ em 1996 (Fig. 3). No final de 1997 houve uma seca pronunciada na região, associada ao fenômeno "El Niño" e o nivel do reservatório baixou a níveis criticos, prejudicando bastante a atividade pesqueira; Nesta ocacião (agosto/97 a janeiro/98), a pesca foi totalmente suspensa, pois não havia condições para descarregamento do pescado.

Ao longo de cada ano nota-se uma variação relativamente grande da produção, sendo que, de modo geral, esta é maior entre os meses de maio a agosto e menor entre outubro e janeiro (Tab. 2). Considerando-se que a área ocupada pelo reservatório é de $2.360 \mathrm{~km}^{2}$, verifica-se que a produção média de pescado em Balbina oscila entre 1,2 a 3,1 kg/ha/ano.

\section{Sócio-Economia da Pesca}

A pesca em Balbina é de natureza comercial e em menor escala, amadora, de caráter esportivo. A comercial é praticada por pescadores profissionais que residem no local permanente ou temporariamente e exercem esta atividade como profissão básica. A pesca amadora é praticada principalmente por turistas de Manaus, de Presidente Figueiredo ou mesmo da própria vila de Balbina, nos finais de semana e feriados.

Os pescadores profissionais estão organizados numa associação de classe, criada em 1990 com o nome de Colônia de Pescadores Z-8, do Município de Presidente Figueiredo (Foram, 1989), e que passou a denominar-se Associação dos Pescadores de Balbina, a partir de 1994. Esta entidade é dirigida por

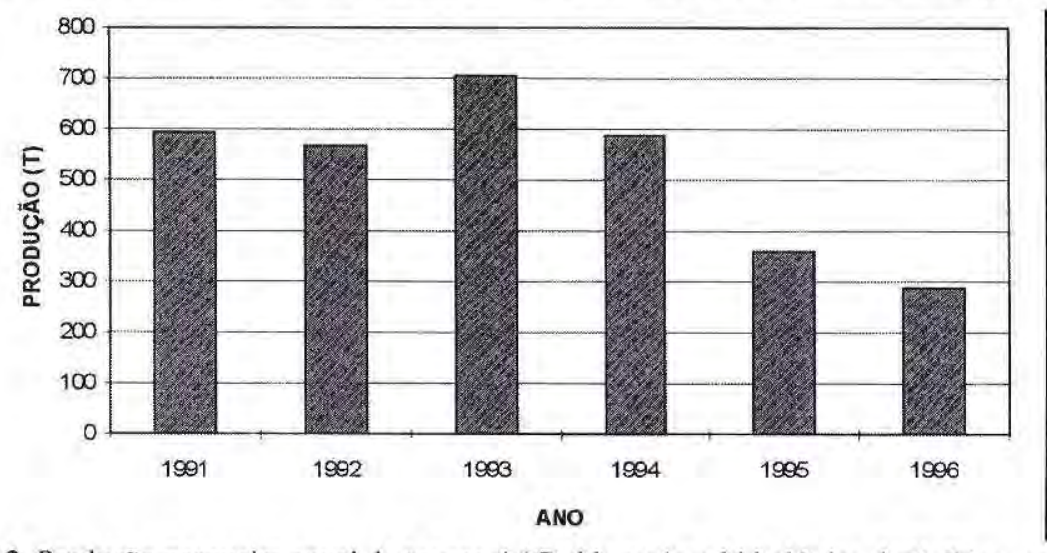

Figura3. Produção pesqueira anual de tucunaré (Cichla spp) na hidrelétrica de Balbina, entre os anos de 1991 a 1996. 
Tabela 2. Produção (t) de tucunaré, no reservatório da UHE Balbina, entre os anos de 1991 e 1997. * Pesca desativada.

\begin{tabular}{llllllllllllll}
\hline & Jan & Fev & Mar & Abr & Mai & Jun & Jul & Ago & Set & Out & Nov & Dez & TOTAL \\
\hline 1991 & & & & & & & & & & & & & 594,4 \\
1992 & & & & & & & & & & & & & 566,1 \\
1993 & 53,7 & 49,8 & 62,5 & 48,3 & 89,8 & 94,8 & 85,5 & 76 & 61,2 & 23,8 & 29,1 & 31,9 & 706,4 \\
1994 & 31,3 & 40,6 & 63,6 & 49,1 & 55,5 & 49,8 & 53,1 & 66 & 51,9 & 45,5 & 52,4 & 31,7 & 590,5 \\
1995 & 20,5 & 26,5 & 23 & 22,7 & 30,6 & 36,6 & 30 & 32,7 & 7,1 & 45,5 & 52,4 & 31,7 & 359,3 \\
1996 & 17,5 & 17 & 21,6 & 23,8 & 30,1 & 37,6 & 30,3 & 41,2 & 28,1 & 14,9 & 13 & 12 & 287,1 \\
1997 & 10,8 & 11,3 & 12,8 & 13,4 & 16,3 & 30 & 28,1 & $*$ & $*$ & $*$ & $*$ & $\star$ & 122,7 \\
\hline TOTAL & $\mathbf{1 3 3 , 8}$ & $\mathbf{1 4 5 , 2}$ & $\mathbf{1 8 3 , 5}$ & $\mathbf{1 5 7 , 3}$ & $\mathbf{2 2 2 , 3}$ & $\mathbf{2 4 8 , 8}$ & $\mathbf{2 2 7}$ & $\mathbf{2 1 5 , 9}$ & $\mathbf{1 4 8 , 3}$ & $\mathbf{1 2 9 , 7}$ & $\mathbf{1 4 6 , 9}$ & $\mathbf{1 0 7 , 3}$ & $\mathbf{3 . 2 2 6 , 5}$ \\
\hline
\end{tabular}

pessoas ligadas à pesca e tem como uma das principais atribuições o controle da produção pesqueira local, o que é feito através da emissão de guias que servem tanto para tributação como para a liberação do pescado, destinado à comercialização.

$\mathrm{O}$ número exato de pescadores que atuam em Balbina não é bem conhecido e também bastante variável, pois há constantes entradas e saidas de pessoas nesta atividade. De acordo com dados da Associação, o maior número deles deu-se em 1992, quando haviam cerca de 300 sócios, entretanto ele decresceu bastante nos anos subsequentes. Em junho/96 existiam cerca de 160 pescadores comerciais e no último levantamento, feito em agosto/97, este número baixou para cerca de 100. Devido à grande extensão do reservatório, a densidade média de pescadores é bastante baixa, entre $0,04 \mathrm{e}$ 0,07 indivíduo por quilômetro quadrado.

Segundo informações do posto de vigilância, localizado na entrada da vila de Balbina, o número de pescadores amadores que se dirigem ao reservatório nos finais de semana oscila em torno de cincoenta. O limite de captura normalmente permitido para o turista é de $30 \mathrm{~kg}$; assim, assumindo-se que este valor seja acatado, a produção média na pesca esportiva seria de 6 toneladas/mês, o que representa de 10 a $24 \%$ da produção pesqueira total do reservatorio de Balbina.

Em cada barco de pesca viajam quatro a cinco pessoas, sendo uma delas chefe de equipe e à qual compete a administração da pesca. No pico de produção, em junho/93, haviam 33 equipes de pescadores profissionais, sendo que na última entrevista, feita em agosto/97, este número havia baixado para apenas 25 .

Cada equipe passa em média seis dias no campo, entretanto este período pode variar entre a metade e o dobro, dependendo do sucesso da pesca. Excetuando-se cerca de três dias gastos entre uma excursão e outra, cada pescador gasta efetivamente cerca de 18 dias na atividade pesqueira. Isso resulta numa produção média individual em torno de $200 \mathrm{~kg}$ por pescaria ou $33 \mathrm{~kg} / \mathrm{homem} /$ dia.

As equipes mantêm uma estreita relação com um comerciante local, que normalmente fornece barco e insumos básicos para a pesca, como combustível e gelo e portanto acaba tendo exclusividade na compra do pescado. Em junho/96, dos sete comerciantes que atuavam em Balbina, quatro possuiam 
dois barcos cada e três outros eram donos dos demais 25 barcos.

Ocasionalmente o pescador prefere alugar o barco; neste caso, cabe a ele todas as despesas, além de uma taxa paga ao proprietário, correspondente a cerca de $200 \mathrm{~kg}$ de pescado. Este tipo de negócio, no entanto, é pouco atraente, sendo mais procurado por pescadores que chegam de Manaus para aventurar nesta atividade.

Parte dos insumos da pesca são adquiridos na própria vila de Balbina, mas praticamente todo o gelo utilizado é trazido de Manaus, em barras de 25 $\mathrm{kg}$, a um custo de R\$1,50. Estas são transportadas em carrocerias de caminhão até o terminal pesqueiro, onde são transferidas manualmente para as caixas dos barcos e levadas aos locais de pesca. Considerando que seu transporte rodoviário dura cerca de 2 horas e que igual período é gasto para sua transferência do caminhão para o barco, conclui-se que o gelo passa aproximadamente 4 horas fora das caixas térmicas, o que representa uma perda considerável.

Ao final das pescarias e antes de ser transferido do barco para o caminhão que o levará ao seu destino final, o pescado volta a ser pesado, desta vez na presença de um fiscal da Associação dos Pescadores. Nesta ocasião é emitida uma nota de produção para cada barco e sobre a qual incide uma taxa de $10 \%$, a ser paga à Associação, sendo que desta, metade compete ao comprador e metade ao pescador. Ainda durante o desembarque, o comprador desconta do pescador os $5 \%$ por ele devidos e garante assumir o pagamento integral de $10 \%$ à Associação. Isso raramente ocorre e neste caso, o pagamento acaba sendo feito em forma de pescado. Pelo fato da Associação não dispor de infraestrutura para acondicionamento do pescado, resulta normalmente que a dívida assumida pelo comprador acaba se perenizando.

Por não dispor de recursos que deveriam ser originados da cobrança das taxas de produção, a Associação sobrevive unicamente das contribuções mensais pagas pelos sócios, que durante o exercício de 1997 era de R\$ 1,5. Apesar do baixo valor, apenas cerca de $30 \%$ dos associados estavam em dias com as mensalidades. É evidente que nesta situação, a Associação não gera recursos nem mesmo para pagar os salários de seus dirigentes e jamais terá condicões de colocar em prática uma política de apoio aos associados, conforme é previsto em seu estatuto.

Praticamente toda a produção pesqueira de Balbina é destinada ao mercado de Manaus, sendo que apenas uma pequena parte é consumida pelos moradores da vila de Balbina. Segundo informações locais, desde o início da atividade pesqueira até por volta de 1992, quase toda a produção era adquirida pelo frigorífico Friuba, localizado na cidade de Iranduba. Nos anos seguintes, a produção voltou a ser comercializada unicamente em mercados e feiras livres de Manaus.

O preço do pescado atualmente pago ao pescador gira em torno de $\mathrm{R} \$$ 0,50 a 0,70 o quilo. Caso o pescador disponha de sua própria embarcaçao para pesca e o comprador tenha fornecido apenas gelo, este adquire o pescado por um preço ligeiramente mais 
elevado, em torno de R $\$ 0,80$ e o entrega em Manaus a cerca de $\mathrm{R} \$ 2,00$ o quilo. $\mathrm{O}$ preço pago pelo consumidor final alcança entre $R \$ 3,50$ e 4,00 o quilo. Isto significa que ao longo da cadeia de comercialização, o pescado chega ao consumidor final com um aumento de até oito vezes, em relação ao preço pago ao pescador.

\section{DISCUSSÃO}

$\mathrm{O}$ incremento da atividade pesqueira no reservatório de Balbina não é um fato inusitado; idêntico fenômeno tem ocorrido com frequência na maioria dos reservatórios de grandes hidrelétricas, em várias partes do mundo (Petr, 1978).

Antes da instalação do reservatório, a pesca comercial no rio Uatumã era realizada apenas no seu curso inferior, próximo à foz. Isso ocorria por duas razões principais: era nesta porção do rio que se localizavam os locais mais piscosos, como lagos situados nas margens do rio e também, porque ai se concentravam os principais povoados da região (Noda \& Noda, 1990). Além disso, o extenso trecho de corredeiras que existiam à montante de Balbina, formavam um grande obstáculo para o transporte fluvial, impedindo ou dificultando a pesca nos cursos médio e superior deste rio.

Exceto na foz do Amazonas e de seus grandes afluentes, a pesca comercial na Amazônia brasileira se dá basicamente em lagos e nos rios de água branca que formam o sistema Solimões/Amazonas (Petrere Jr., 1978); assim sendo, cursos médio e superior de rios de pequeno a médio porte e com águas escuras, como o Uatumã, são explorados apenas pela pesca de subsistência.
Diante disso, fica evidente que a pesca foi influenciada positivamente com a instalação do reservatório de Balbina. Há de se considerar, no entanto, que o represamento do rio Uatumã ocasionou uma drástica redução da diversidade ictiofaunistica, eliminando da área sob influência do reservatório algumas espécies de alto valor, como o pacu-cana, Mylesinus paraschomburgkii, um peixe de grande porte, abundante nas corredeiras, importante na pesca de subsistência (Santos et al., 1997).

$\mathrm{O}$ trecho do Uatumã, localizado à jusante de Balbina, também foi fortemente impactado, sobretudo nos primeiros três anos de funcionamento da hidrelétrica, por causa da diminuição do teor de oxigênio da água evertida pelas turbinas e que ocasionalmente provocava mortandade de peixes. Como as comunidades desta área tinham fortes vinculações com o rio, esta situação acabou gerando consequências desastrosas não somente para a pesca, mas também na saúde e no quotidiano das pessoas que ali viviam.

Apesar de haver nos reservatórios uma tendência natural à estabilização após a reciclagem dos nutrientes, sabese que o represamento de um rio produz impactos com consequências duradouras e quase sempre irreversíveis para as comunidades de peixes (Agostinho et al.,1992). Estudos em andamento sobre a ictiofauna do Uatumã, na área de Balbina, mostram que a diversidade é extremamente baixa, comparável à que se encontrava nesta área, em condições naturais (Eletronorte/INPA, 1983).

Mesmo considerando que a 
pesca em Balbina tenha tido um impacto positivo decorrente da instalação do reservatório, observa-se que o rendimento é muito pequeno, quando comparado com o de outras regiões do Brasil. Em Tucurui, a produção de pescado é estimada em 5 $\mathrm{kg} / \mathrm{ha} / \mathrm{ano}$ (Ribeiro et al., 1995), ou seja, quase o dobro da verificada no reservatório de Balbina, que é de 1,2 a $3,1 \mathrm{~kg} / \mathrm{ha} / \mathrm{ano}$. Em Itaipu, a produção é ainda maior, em torno de $12 \mathrm{~kg} / \mathrm{ha} /$ ano (Petrere Jr., 1996).

Dois fatores básicos podem estar relacionados a esse baixo rendimento pesqueiro: o primeiro, é que, ao contrário do que ocorre em outros reservatórios, onde várias espécies são explotadas, em Balbina a pesca está baseada quase que unicamente sobre $o$ tucunaré. Curiosamente, peixes comerciais, bastante comuns em outras hidrelétricas amazônicas, como pescada (Plagioscion spp) e peixes lisos (pimelodídeos), não ocorrem comumente no reservatório de Balbina. $\mathrm{O}$ segundo, é que as águas do Uatumã são relativamente pobres em nutrientes e portanto têm uma produção biológica baixa, em relação a outros sistemas fluviais da Amazônia e demais regiões, onde se encontram a maioria dos reservatórios.

Em termos comerciais, o único peixe explotado em Balbina é o tucunaré. Em Tucurui/PA, este peixe representa $57 \%$ da produção pesqueira, entretanto cerca de 49 outras espécies são também explotadas, destacando-se entre elas a pescada (Plagioscion sp), com 26\% da produção total (Petrere Jr., 1996). Em Samuel/RO, além do tucunaré são pescados intensamente o aracu - Schizodon fasciatus e o sorubim - Pseudoplatystoma fasciatum (Santos, 1996).

Além do tucunaré, foram identificadas cerca de 70 outras espécies de peixes no reservatório de Balbina (dados não publicados), sendo que pelo menos quatro delas, apresentam potencial para a pesca, por serem muito abundantes e alcançarem porte razoável: a piranha preta (Serrasalmus rhombeus); carás (Satanoperca jurupari e Geophagus sp) e oranas (Hemiodus argenteus). Destas, merece destaque a primeira, da qual já se faz um aproveitamento incipiente, apenas em forma de filé.

A piranha preta é uma das principais espécies de peixes que proliferaram nos reservatórios de CuruáUna (Ferreira,1984), Samuel (Santos, 1996), bem como nos demais reservatórios da Amazônia. Por sua grande abundância e porte (cerca de 40 $\mathrm{cm}$ e $3 \mathrm{~kg}$ de peso), esta espécie apresenta enorme potencial econômico, não somente para a pesca esportiva e consumo direto, mas também para a indústria turistica, que explora o peixe inteiro fixado e sub-produtos, como arcadas dentárias.

A proliferação de tucunaré, verificada em todos os reservatórios de hidrelétricas da Amazônia tem-se dado espontaneamente, a partir de estoques naturais que existiam na área. O crescimento das populações desta espécie ocorre de maneira rápida, pois os sinais de abundância e o concomitante desencadeamento da pesca sobre seus estoques têm começado apenas cerca de um a dois anos após a formação do reservatório. Apesar da existência de 
uma pesca intensiva e voltada exclusivamente para a sua explotação, as populações de tucunarés nos reservatórios amazônicos têm-se mantido como dominantes, em relação aos demais peixes colonizadores destes ambientes.

O tucunaré é originário da bacia amazônica e um dos peixes mais populares e apreciados na culinária regional. No ambiente natural, ele ocorre em diferentes biótopos, mas demonstra preferência por lagos, onde é intensamente pescado, sobretudo na época de seca. Devido ao alto valor comercial e à sua capacidade de reproduzir em cativeiro, ele tem sido introduzida em várias regiões, sobretudo em açudes do nordeste e mais recentemente em reservatórios do sudeste brasileiro.

O tucunaré foi introduzido acidentalmente no Lago Gatum, na zona do canal de Panamá, em 1969 e alguns anos depois já se constituia numa espécie dominante, tendo provocado uma grande dizimação da fauna local (Zaret, 1973). Segundo Maturell \& Tapia (1989), desde o momento da introdução desta espécie, vem-se desenvolvendo na região uma intensa atividade pesqueira, tanto na pesca comercial, de subsistência e também desportiva. A partir de 1980 até os dias atuais, as ações voltadas à promoção e organização da pesca naquela área temse aprimorado, havendo registros regulares de captura e esforço pesqueiro e o monitoramento de seus estoques.

De acordo com Fernando \& Holcik (1991), a ictiofauna que se desenvolve em reservatórios é constituida por espécies que já ocorriam originalmente no sistema hidrográfico. Ainda segundo estes autores, o número de espécies de peixes presentes num reservatório é invariavelmente menor que nos trechos do mesmo rio não submetidos a represamento, o que se dá por causa da redução do número de habitats, bem como pela incapacidade da maioria das espécies fluviais de se adaptar ao ambiente lacustre.

A redução da diversidade da ictiofauna em reservatórios é acompanhada do aumento da frequência de determinadas espécies, que normalmente passam a dominar este ambiente. Em levantamentos feitos em vários rios de Rondônia, onde a diversidade é bastante elevada, as abundâncias relativas de cada espécie não ultrapassam $30 \%$, mas em ambientes alterados a diversidade é drasticamente reduzida, sendo que certas espécies atingem frequências de até $70 \%$ (Santos, 1991).

Este fenômeno mostra que há uma relação direta entre a biodiversidade e a diversidade das condições ecológicas. É neste tipo de fato que está baseado o princípio biocenótico de Thienamann (Dajoz, 1973), o qual assegura que, quando as condições do meio são favoráveis, encontram-se numerosas espécies, sendo cada uma delas representada por um pequeno número de indivíduos; ao contrário, quando as condições são desfavoráveis, só se encontra um pequeno número delas, mas cada uma em geral representada por numerosos indivíduos.

Na maioria dos casos, os peixes dominantes em reservatórios são espécies predadoras, não migradoras e que têm preferência por habitats 
lênticos. Exemplo disso ocorreu nas hidrelétricas de Curuá-Una (Ferreira, 1984) e Samuel (Santos, 1996), onde houve a proliferação de tucunaré (Cichla spp) e piranha preta (Serrasalmus).

Além destas espécies comuns, que parecem ter proliferado em praticamente todos os reservatórios amazônicos, algumas outras ocorrem com grandes abundâncias apenas em alguns deles, como é o caso de Schizodon fasciatus (aracu comum), uma espécie herbivora que proliferou na hidrelétrica de Samuel (Santos, 1996) e da pescada (Plagioscion sp, carnivora) e curimatã (Prochilodus nigricans, iliófaga), as quais proliferaram no reservatório de Tucuruí (Petrere Jr., 1996).

Estes fatos servem para evidenciar que apesar das aparentes semelhanças, cada reservatório tem características próprias e portanto, uma composição ictiofaunística distinta. A proliferação de determinadas espécies de peixes em cada um deles deve estar relacionada não somente à pré-adaptação das espécies que são comuns aos diversos rios, mas à combinação de diversos parâmetros ambientais que irão se estabelecer em cada um deles, após o represamento.

$\mathrm{O}$ amontoado de troncos e galhos que resultou da morte da floresta alagada pelo represamento constitui-se num biótopo importante como abrigo de várias espécies de peixes, sobretudo as formas jovens e de pequeno porte e como substrato de desova para o tucunaré. Além disso, é também um ambiente propício ao desenvolvimento do perifiton, formado por algas e microscustáceos, o qual é fonte básica da alimentação para várias espécies de peixes, que ali se desenvolveram, destacando-se entre eles as oranas (Hemiodontídeos) e piabas (Characídeos). Assim sendo, é evidente que a queimada deste material, que vem sendo praticada nas proximidades das ilhas, quando o nivel dágua está bastante baixo, representa um grande dano à vida dos peixes.

A densidade de pescadores no reservatório de Balbina é bastante inferior à média encontrada em reservatórios de outras regiões, como em Tucuruí, que é da ordem de 0,8 e no Nordeste brasileiro, que é de 3,2 pescador/ $\mathrm{km}^{2} /$ ano (Petrere Jr., 1996). Em alguns reservatórios da África, a densidade chega a cerca de 30 pescadores/ $\mathrm{km}^{2}$ (Petrere Jr. \& Agostinho, 1993). Segundo Welcomme (1990), uma densidade em rios da América do Sul inferior a 0,5 pescador $/ \mathrm{km}^{2} /$ ano indica que a área está sendo sub-explotada.

Dentre os grandes sistemas aquáticos naturais da Amazônia e dos quais se dispõe de dados de pesca comparativos, apenas o rio Negro apresenta uma densidade inferior ao reservatório de Balbina $(0,04 /$ pescador $/ \mathrm{km}^{2}$, segundo Ribeiro \& Petrere Jr., 1990). Este rio apresenta águas pretas e é considerado como tendo baixa produtividade biológica e poucas espécies explotáveis pela pesca comercial, exceto cardumes de jaraquis durante suas migrações entre este e o sistema de águas brancas do rio Solimões/Amazonas.

Considerando-se os baixos níveis de produção pesqueira de Balbina, como decorrentes apenas da baixa densidade de pescadores, fica a impressão de que os recursos 
pesqueiros ainda se encontram numa fase de sub-explotação. Observa-se, no entanto, que a produção tem apresentado uma tendência de declínio ao longo dos anos, havendo também indícios de que os niveis de produção máxima já tenham sido atingidos. Outro fator que corrobora esta hipótese é que o tamanho dos peixes capturados vem decrescendo sistematicamente. Segundo os pescadores, nos primeiros anos de pesca, o tamanho médio do tucunaré oscilava em torno de 30 a $35 \mathrm{~cm}$; atualmente esse se situa em torno de 24 a $27 \mathrm{~cm}$, havendo uma grande parcela dos peixes comercializados com tamanhos inferiores a $20 \mathrm{~cm}$.

Devido a este conjunto de fatores e aos vários interesses sócio-econômicos e politicos que normalmente tem influências sobre o setor pesqueiro, já existem polêmicas a respeito da necessidade ou não de se adotar medidas para o adequado gerenciamento da atividade pesqueira em Balbina; o leque de alternativas defendidas abrange a suspensão temporária da pesca comercial até sua substituição total pela pesca esportiva, de cunho turístico.

Além da hidrelétrica, Balbina conta com uma invejável paisagem cênica, representada por cachoeiras e cavernas, o que, aliado à sua proximidade de Manaus, lhe assegura grande potenialidade turistica. Assim sendo, é evidente que a pesca esportiva no reservatório seja um dos principais instrumentos para o desenvolvimento do turismo regional.

Como meio de incrementar a atividade pesqueira em Balbina, algumas técnicas de manejo dos estoques devem ser implementadas. Dentre estas merece especial atenção a explotação multiespecífica, ou seja, o aproveitamento de outras espécies de peixes, ainda não explotadas, com destaque para a piranha-preta. Além de permitir o aproveitamento de pescado com grande disponibilidade no ambiente, sua captura pode servir como instrumento de descompressão da pesca sobre os estoques de tucunarés.

Talvez pelo grande número de espécies de peixes comerciais disponiveis nos rios amazônicos, a piranha preta não tenha uma participação significativa na composição do pescado regional, entretanto, por causa da fama lendária, sobretudo a de que sua carne é afrodisíaca e também por ser um peixe carnivoro, facilmente capturável com anzol, esta espécie apresenta um potencial extraordinário para a pesca esportiva.

A pesca em Balbina originou-se de um processo totalmente informal e ao longo de sua trajetória não tem tido nenhum apoio direto e substancial do poder público. Todas as etapas envolvidas no processo de captura, transporte e comercialização do pescado são realizadas por pescadores e comerciantes locais e a maioria delas é bastante deficiente.

Um dos principais fatores responsáveis pela oscilação dos níveis de produção e rendimento econômico da pesca do tucunaré em Balbina é a forte concorrência do pescado oriundo de outros rios amazônicos, sobretudo no periodo da vazante, em que normalmente a oferta de pescado é acentuada.

A relação de interdependência entre o mercado de Manaus e de Balbina foi bastante intensificada com a 
melhoria das condições de transporte, propiciada pelo asfaltamento da BR 174, que liga Manaus a Balbina. Ultimamente tem havido inclusive uma alternância na destinação de pescado entre estes dois centros. Em julho e agosto/97 estava sendo comercializado, na vila de Balbina e ao longo da estrada entre esta e Presidente Figueiredo, uma grande quantidade de pescado proveniente de Manaus, constituído basicamente de pacu (Mylossoma duriventre) e curimatã (Prochilodus nigricans).

$O$ preço do pescado na maior parte dos mercados da Amazônia brasileira tem-se mantido relativamente estável durante os últimos anos por causa de uma politica em vigor e que tem como base o controle inflacionário. O preço do tucunaré, pago ao pescador em Balbina é de cerca de $\mathrm{R} \$ 0,50$ o quilo, sendo aproximadamente o mesmo pago em outras regiões da Amazonia (Isaac et al., 1996).

Um dos proncipais problemas enfentados nos últimos anos pelos pescadores profissionais de Balbina é a forte concorrência da pesca esportiva no reservatório. Além desta ser dispensada de qualquer taxa direta sobre o pescado, a intensa movimentação dos barcos motorizados dos pescadores esportivos contribuem para o afugentamento dos peixes das áreas mais próximas à barragem e ao canal principal do rio, fazendo com que os pescadores profissionais tenham que se deslocar para áreas mais afastadas para o exercício de suas atividades, onerando, assim, $\mathrm{o}$ custo da sua produção.

A pesca esportiva no reservatório de
Balbina já está totalmente consolidada, tanto assim que já está incluída oficialmente, como festival anual do tucunaré, no calendário turístico do município de Presidente Figueiredo.

Geralmente em áreas represadas a pesca não se constitui numa atividade isolada e única. Ao contrário, já há um certo consenso de que elas devam servir para usos múltiplos e também integrados com outras atividades sócio-econômicas. Esta prática já é bastante comum em reservatórios de vários países desenvolvidos e onde neles se desenvolvem atividades integradas nos campos da cultura, lazer, turismo, entre outros. Em reservatórios de países populosos como a Tailândia e Estados Unidos, onde a pesca esportiva é muito difundida, esta chega a atingir um valor e importância igual ou maior que o alcançado pela energia elétrica por eles produzida (Lowe McConnell, 1973).

Uma análise, mesmo que superficial, mostra que a pesca se constitui numa das principais alternativas sócio-econômicas para os moradores da vila de Balbina. Assim sendo, é evidente que os interesses envolvidos na pesca profissional e amadora devem ser compatibilizados e os recursos pesqueiros explotados de maneira sustentável.

A sustentabilidade dos seus recursos pesqueiros deve ser embasada por conhecimentos técnico-cientifico, mas esta só se mantém de fato através da conscientização e participação da comunidade e de todos os usuários do recurso, num processo integrado de gestão. Além disso, esta estratégia deve contemplar não somente o campo da 
atividade pesqueira, mas se estender também a outras atividades a ela interligadas e mutuamente dependentes, como a agropecuária, mineração e turismo.

Para que a eficácia desta ação seja assegurada e, sobretudo, que a preservação dos estoques seja garantida, a gestão dos recursos pesqueiros em Balbina, como também nos demais reservatórios já instalados na Amazônia, deve ter como premissas básicas a conservação da máxima biodiversidade, a conservação das áreas naturais do entorno, o engajamento da comunidade na defesa ambiental e um esforço constante, tanto coletivo como individual, para que os lucros e beneficios gerados sejam distribuídos de maneira mais justa e equitativa e tenham o maior alcance social possivel.

\section{AGRADECIMENTOS}

Os autores agradecem aos colegas Maria Dayse e J. Pierre, do Laboratório de Limnologia da Eletronorte pelo apoio às excursões e fornecimento de dados sobre as características da água; à Associação dos pescadores de Balbina pela cessão dos dados de desembarque; ao sr. Francisco (Chiquinho) e equipe de pescadores pelas informações sobre a pesca e cooperação nos trabalhos de campo; ao colega Jansen Zuanon e aos referees pelas valiosas sugestões.

\section{Bibliografia citada}

Agostinho, A. A.; Júlio Jr, H.F.; Borghetti, J.

R. 1992. Considerações sobre os impactos dos represamentos da ictiofauna e medidas para sua atenuação. Um estudo de caso: reservatório de Itaipu. Unimar, 14 (suplemento): 89-107
Bayley, P. B.; Petrere Jr. M. 1989. Amazon fisheries: assessment methods, current status and management options. Proc. Intern. Large River Symp.: 385-398.

Camargo, A. F. M.; Miyai, R. K. 1983. Estudos de ecologia e controle ambiental na região do reservatório da UHE de Balbina. Segmento: Relatório setorial Limnologia/Macrófitas aquáticas. Convênio ELETRONORTE/CNPq/ INPA. Agosto/83: 08-59

Dajoz, R. 1973. Ecologia geral. Ed. Vozes / Edusp. 472p

ELETRONORTE. s.d. Ambiente - Desenvolvimento. Balbina. Catálogo informativo. 24p

ELETRONORTE/INPA/CNPq 1983. Estudos de meio ambiente na área de influência da hidrelétrica de Balbina - Rio Uatumã. Estimativa da ictiofauna. Relatório semestral/Julho/83: 61-67

Fernando, C. H.; Holcik J. 1991. Fish in reservoirs. Int. Revue Ges. Hydrobiol., 76(2): 149-167

Ferreira, E. J. G. 1984. A ictiofauna da represa hidrelétrica de Curuá-Una, Santarém, Pará. I. Lista e distribuição das espécies. Amazoniana, VIII (3): 351-363

Foram - Forum Permanente de Debates da Amazônia, 1989. Situação do rio Uatumã á jusante da hidroelétrica de Balbina. Relatório Técnico. 24p (mimeografado)

Furtado, L. G. 1981. Pesca artesanal: um delineamento de sua história no Pará. Bol. Mus. E. Goldi, Antropol., 79: 1-50

Goodland,R .J.A.; Juras, A.; Pachauri, R. 1993. Can hydro-reservoirs in tropical moist forest be environmentally sustainable?. Environmental Conservation, 20(2): 122-130

Holanda, O. M. 1982. Captura, distribuiçào, alimentação e aspectos reprodutivos de Hemiodus unimaculatus (Bloch, 1794) e Hemiodopsis sp. (Osteichthyes, Characoidei, Hemiodidae), na represa hidrelétrica de Curuá-Una. Pará. Dissertação de mestrado, INPA/FUA, Manaus, 99p.

Isaac, V. J.; Milstein, A.; Ruffino, M. L. 1996. A pesca artesanal no baixo Amazonas: análise multivariada de captura por espécie. Acta Amazonica, 26 (3): 185-208

Leite, R. G.; Zuanon, J. A. S. 1991. Peixes 
ornamentais - aspectos da comercialização, ecologia, legislação e propostas de ações para um melhor aproveitamento. In: Val, A.L.; Figliuolo, R.; Feldberg, E. (eds) Bases cientificas para estratégias de preservação $e$ desenvolvimento da Amazônia: fatos e perspectivas. Vol. I pp 327-330.

Lowe-McConnell, R. H. 1973. Summary: reservoirs in relation to man fisheries. In: Ackerman, W.C.; White, G.F.; Worthington (ed): Man-made lakes: their problems and environmental effects. 2nd part. 641-653

Maturell, G.; Tapia, F. 1989. La pesqueria de Cichla ocellaris en el lago Gatun, Panamá. In: Segundo Taller Internacional sobre ecologia y manejo de peces en lagos y embalses. Rela. Téc. FAO: 91-96

Merona, B. de. 1993. Pesca e ecologia dos reecursos aquáticos na Amazônia, pp 159185. In: Furtado, L.G. Leitão, W.; Mello, A.F. (eds). Povos das águas. Realidae e perspectivas na Amazônia. Mus. Par. E. Goeldi, Belém PA, 292p.

Noda, S. N.; Noda, H. 1990. A água envenenada. Ciência Hoje, vol 11(64): 40-42.

Okada, E. K.; Agostinho, A. A.; Petrere M. 1996. Catch and effort data and the management of the commercial fisheries of Itaipu reservoir in the upper Parana river, Brazil. In: Cowx, I.G, (ed.). Stock Assesment in Inland Fisheries pp. 155161. Fishing News Books, Bodman.

Oliveira Jr., A.B. - 1998. Táticas alimentares e reprodutivas do tucunaré (Perciformes, Cichlidae) no reservatório da UHE Balbina, AM., Brasil. Dissertação de Mestrado, INPA/FUA, Manaus,AM.,

Petr, T. 1978. Tropical man-made lakes - their ecological impact. Arch. Hydrobiol, 81 (3): $368-385$

Petrere Jr. M. 1978. Pesca e esforço de pesca no estado do Amazonas. II. Locais, aparelhos de captura e estatisticas de desembarque. Acta Amazonica, 8 (3): supl. 2

Petrere Jr., M. 1992. As comunidades humanas ribeirinhas da Amazônia e suas transformações sociais, In: Dieges,A.C. (Org.) Populações humanas, rios e mares da Amazônia. Proceedings of the IV Encontro de Ciências Sociais e o Mar no Brasil, São Paulo, SP. PPCAUB-
USP: $31-63$

Petrere Jr., M. 1996. Fisheries in large tropical reservoirs in South America. Lakes.; Reservoirs: Research and management, 2: $111-133$

Petrere, M.; Agostinho, A. A. 1993. La pesca en el tramo brasileno del rio Paraná. FAO FIPT/ R490, Rome, Italy. 72p (mimeografado)

Ribeiro, J. S. B. 1984. Estudos de Ecologia e controle ambiental na região do reservatório da UHE de Balbina. Segmento Limnologia. Convênio ELN/CNPq/INPA. Julho/dezembro/ 84: $1-21$

Ribeiro, M. C. L. B.; Petrere Jr., M. 1990. Fisheries ecology and management of the jaraqui (Semaprochilodus taeniurus, S. insignis) in central Amazonia. Regulated Rivers Research; Management, vol. 5: 195-215

Ribeiro, M. C. L. B.; Petrere Jr; Juras, A. A. 1995. Ecological integrity and fisheries ecology of the Araguaia - Tocantins river basin, Brazil. Regulated Rivers: Research; Management, vol, 11: 325-350

Santos, G. M. 1991. Pesca e ecologia dos peixes de Rondônia. Tese de doutorado. INPA/FUA, Manaus, AM., 213p

Santos, G. M. 1996. Impactos da hidrelétrica Samuel sobre as comunidades de peixes do rio Jamari (Rondônia, Brasil). Acta Amazonica, 25 (3/4): 247-280.

Santos, G. M.; Pinto, S. S,; Jegu, M. 1997. Alimentação do pacu-cana, Mylesinus paraschomburgkii (Teleostei, Serrasalmidae), em rios da Amazônia brasileira. Rev. Bras. Biol., 57(2): 311-315.

Sioli, H. 1967. Studies in amazonian waters. In: Atas do Simpósio sobre a biota amazônica. (Limnologia), 3: 9-50

Vieira, I. 1982. Aspectos sinecológicos da ictiofauna de Curuá-Una, represa hidrelétrica da região amazônica. Tese de livre docência, Univ. Fed. Juiz de Fora, MG., 104p

Welcomme, R. L. 1990. Status of fisheries in South America rivers. Interciencia, 15: 337-345

Zaret, T; Paine, R. T. 1973. Species introduction in a tropical lake. Science, 182: 449-455

\section{Aceiito para publicação em 26.08.98}

